\title{
Accredited Social Health Activist (ASHA) and Her Role in District Mental Health Program: Learnings from the COVID 19 Pandemic
}

\author{
Patley Rahul ${ }^{1} \cdot$ K. Rakesh Chander ${ }^{1} \cdot$ Manisha Murugesan $^{1} \cdot$ Adarsha Alur Anjappa $^{2} \cdot$ Rajani Parthasarathy $^{2}$. \\ Narayana Manjunatha ${ }^{1}$. Channaveerachari Naveen Kumar ${ }^{1}$. $\cdot$ Suresh Bada Math ${ }^{1}$
}

Received: 27 September 2020 / Accepted: 2 January 2021 / Published online: 16 January 2021

(C) The Author(s), under exclusive licence to Springer Science+Business Media, LLC part of Springer Nature 2021

\begin{abstract}
COVID 19 pandemic has posed challenges for public mental healthcare delivery, particularly in LAMI countries such as India. However, this unique situation has also brought in opportunities to revisit the health system and optimally utilize the available resources. In this brief report, we report one such new initiative in which existing community health workers (CHWs), known as ASHAs (Accredited Social Health Activist) acted as a bridge between patients with mental illness and the District Mental Health Program (DMHP) of Ramanagara district of Karnataka State, India. They maintained continuity of care of 76 patients by delivering mental healthcare services to the patients' doorstep. This has paved the way to rethink and revisit their role in public mental healthcare delivery not only during COVID 19 times, but also beyond.
\end{abstract}

Keywords Accredited Social Health Activist (ASHA) · Community Healthcare Worker $(\mathrm{CHW}) \cdot$ District Mental Health Programme (DMHP) · COVID 19

Channaveerachari Naveen Kumar

cnkumar1974@gmail.com

Patley Rahul

rahulpatley@gmail.com

K. Rakesh Chander

kchander1810@gmail.com

Manisha Murugesan

m.manisha92@gmail.com

Adarsha Alur Anjappa

adarsha8@gmail.com

Rajani Parthasarathy

drrajanibalaji@gmail.com

Narayana Manjunatha

manjunatha.adc@gmail.com

Suresh Bada Math

sureshbm@gmail.com

1 Community Psychiatry Unit, Department of Psychiatry, National Institute of Mental Health and Neuro Sciences (NIMHANS), Bengaluru, Karnataka 560029, India

2 Department of Health and Family Welfare, Government of Karnataka, Bengaluru, Karnataka, India

\section{The Context}

Ramanagara is a rural district in Karnataka, a South Indian State. In March 2020, the lockdown was announced in India due to COVID 19 and consequently, the mental healthcare delivery system was adversely affected. However, this scenario created unique opportunities to review and redefine the role of existing Community Healthcare Workers too (particularly the Accredited Social Health Activists; ASHAs). In this report, we wish to bring to light, an initiative that hitherto did not exist in public mental health care delivery in India: the role of ASHAs in ensuring continuity of care for those with severe mental illnesses'. These experiences have the potential to inform a transformational change in their (and similar other community healthcare workers') larger role in public mental healthcare delivery in India.

\section{District Mental Health Program (DMHP) of Ramanagara}

DMHP services in Ramanagara has been functional since 2016. The activities includes (1) clinical services for new and follow up patients, (2) Information, Education and Communication (IEC) activities to create awareness about mental 
illness and reduce stigma, and (3) training of medical officers, para medical staff, teachers, firemen, Anganwadi worker and ASHAs worker as part of capacity building. Other innovative programs like Manochaitanya, Manasadhara, Manasakendra, Dawa-Dua, Primary Care Psychiatry Program and e-monitoring software for DMHP have been successfully implemented (Manjunatha et al. 2020). Along with these, there are targeted interventions like Care at Doorsteps, School Mental Health Programme, College Counselling Programme, Workplace Stress Management Programme, District Counselling centres and crisis helpline etc. The activities of the Ramanagara DMHP has increased from 2016 (the time when it became fully operational) to the present. The number of patients served has increased to four times what it was initially. To date, around 17,962 patients have been served by this DMHP team. Table 1 depicts the yearly statistics of the camps and number of patients who have received care under the DMHP program in Ramanagara.

\section{Role Played by the ASHAs in Ramanagara DMHP During the COVID 19 Pandemic}

After the onset of pandemic, because of the lockdown and travel restrictions, many persons with mental illnesses did not have access to services and hence ran the risk of discontinuing essential medications (that are essential for continuity of their care) which could have resulted in the relapse of their illness leading to rehospitalisation, poor psychosocial outcomes, poor quality of life, reduce effectiveness of subsequent treatment and increased suicide (Semahegn et al. 2018). After liaising with the DMHP team (headquartered in the District hospital), ASHAs made a list of such patients (who required medications), collected the same, and ensured their availability to the needy. For such patients who were able to go to the nearby primary health centres (PHCs), medications were made available there. More importantly, for those who were unable to travel, medication delivery was ensured at their respective homes with adequate COVID safety measures such as social distancing and wearing masks while interacting with the patients. They also encouraged patients to use these safety precautions and to reach out to

Table 1 Yearly statistics of DMHP activities in Ramanagara

\begin{tabular}{lll}
\hline Year & Number of camps & $\begin{array}{l}\text { Num- } \\
\text { ber of } \\
\text { patients }\end{array}$ \\
\hline August 2016-March 2017 & 43 & 1596 \\
April 2017-March 2018 & 115 & 4665 \\
April 2018-March 2019 & 105 & 5605 \\
April 2019-March 2020 & 108 & 6096 \\
\hline
\end{tabular}

local hospital if they have symptoms of COVID. All these patients were already diagnosed and were known to DMHP care. During these visits, wherever necessary, teleconsultations were provided by the DMHP Psychiatrist as per the Telemedicine guidelines of India. Although medications had previously been sent by courier, use of ASHAs in this role was novel. Along with medication delivery, brief counselling was also carried out, focusing on psychoeducation, the importance of treatment adherence and common adverse effects of psychotropics. In total, 76 patients (36-psychosis, 20-bipolar disorder, 7-intellectual disability, 5-epilepsy, 3-depressive disorder, 3-obsessive compulsive disorder) were identified and the necessary psychotropic medications like antipsychotics, mood stabilisers, antidepressants were delivered between April and May 2020. The patients were given medications for a period of 2 months along with the contact number of the social worker of the team for emergency and continuity of care. None of them were on depot injectables. All patients appreciated the fact that some sort of help could reach them during these testing times. This was a proactive outreach activity that has not been documented before. It is reasonable to assume that these patients may have discontinued the treatment without this initiative.

\section{Learnings About the Potential for a Larger Role of Community Healthcare Workers in Public Mental Healthcare Delivery}

The Alma Atta Declaration in 1978, recognised that key to the community health is the provision of primary health care and this realization has led to the utilisation of community health workers (CHWs) for achieving this goal (WHO, 1978). CHWs work in the community, selected by and answerable to the community for whom they work. They receive briefer training than the health care professionals and are supported by the health system (Frankel and Doggett 1992). They help the doctors and nurses in activities such as health promotion and serve as "helping hands" (Scott and Shanker 2010; Walt and Gilson 1990). In low and middle income countries (LAMICs), they play a key role in delivering services in the health system to the poor and underserved populations and thus bridge the human resource and financial gaps (WHO, 2007). The roles, responsibilities, training and incentives for the CHWs vary across the world according to the programs in which they are involved.

India's flagship program in health, National Rural Health Mission (NRHM) launched in 2005 initiated the Accredited Social Health Activist (ASHA) Programme with the aim of community participation in the health system. ASHAs are female community health workers and they form one of the world's largest community health 
Table 2 Recommendations to improve ASHA workers role in mental health services

(a) Ensuring adequate training of ASHA workers in mental health

(b) Allocation of performance-based incentives for mental health related services

(c) Appropriate supervision and provision of necessary resources (like medications) to perform their tasks.

(d) Enabling ASHA workers to use the technology

Example: for ensuring treatment adherence by sending SMS text messages, quick reporting of cases during the epidemics, alerting next

level of health services regarding emergencies and creating awareness about emerging health issues or health programmes

(e) Modification of role of ASHA worker as per the recommendations of National Mental Health Policy group and Ayushman Bharat initiative

(f) Utilising the centres like NIMHANS to train the ASHA workers in mental health using the Telemedicine services

(g) Planning mobile apps for the training of ASHA workers.

force (Liu et al. 2011). Each ASHA caters to one thousand people and they serve as the link between the government health care services and the community, mitigating the cultural and social barriers and enhancing the community participation (Lipekho et al. 2015). They receive service and performance-based incentives for performing their primary duties such as referral and escort services for institutional deliveries and facilitating immunisation (Wang et al. 2012). However, utilizing services of ASHA workers for mental health was not existent. This has started to change. Apart from the above example, there are a couple of reports of their role in psychiatric case-finding (Reddy et al. 2014; Ibrahim et al. 2020). The authors believe that unlike the other non-communicable diseases like Hypertension and Diabetes (Abdel-All et al. 2019), ASHAs can easily fit into the mental health system and the mental health work can easily be integrated into their routine without any extra burden. For example, quick screening, counselling and referral to treatment centres and other social welfare agencies can easily be achieved. Efforts in the past were less successful for non-communicable diseases because the tasks involved certain medical procedures such as measuring blood pressure and blood glucose levels which are considered difficult by the CHWs.

As part of the DMHP, the CHWs like ASHAs can be trained in identification, referral and delivering simple psychosocial interventions. They also can play a role in overcoming barriers for acceptability of mental health services in the community such as stigma, myths, and lack of awareness (Rasaily et al. 2017). Such training is happening in states such as Karnataka where almost 40,000 ASHA workers have been trained in the field of mental health. The training includes recognition of mental health disorders such as schizophrenia, depression, anxiety and alcohol use disorders, basic counselling, and referral to the treatment centres (Armstrong et al. 2011; Kallivayalil 2018).

Research projects in the communities have shown that lay health workers can effectively be used in task shifting for depressive disorders. This has been shown to be costeffective (Buttorff et al. 2012). The Ministry of Health and Family Welfare, Govt. of India has made provision for two
CHWs per Primary Health Centre (PHCs) dedicated to deliver mental health services (Policy Group 2012). The Ayushman Bharat Initiative through the establishment of Health and wellness centres (HWCs) also proposes that the health services (including dispensing medicines) should be delivered by non-physician health workers, mid-level health providers, Multipurpose and ASHA workers (Mishra 2012). ASHAs have a respected position in their local communities and can be effectively integrated into the existing health systems. Communities will respond better if ASHAs engage them with regard to mental health (Mishra 2012). ASHA programme provides an opportunity to improve the mental health services through supporting communities to access treatments, reducing the pressure on the health system, bringing in-depth knowledge about the villages, and facilitating the community participation in the health programmes. However, some of the challenges still remain like (1) not to overburden ASHAs, (2) not to diminish the quality of care of services they currently provide as they take on new tasks, (3) to determine whether to recruit new cadre or to work with existing cadres of ASHAs. Table 2 shows some of the recommendations to overcome these challenges.

Finally, we need more studies to test the effectiveness of CHWs in detection and as well as referral of people with mental health issues. CHW programmes must be adequately resourced and should have strong monitoring, evaluation, and quality assurance systems in order to be effective so that they can continually improve and help in bridging the treatment gap and reducing the burden of mental illness.

Acknowledgements We would like to thank Ms. Padmarekha (Psychiatric Social Worker), Ms. Rachavva (Psychiatric Nurse), Ms. Pavitra (Community nurse), Ms. Kamala (data entry operator) of the Ramanagara DMHP for their insights and inputs without which the study could not have been accomplished. The entire DMHP team, Ramanagara district, Karnataka for their tireless efforts in serving the persons with mental illness and their families, and for contributing with their inputs in this process.

Funding We declare that there is no funding from any organization or pharmaceutical company. 


\section{Compliance with Ethical Standards}

Conflict of Interest We declare that there is no conflict of interest.

\section{References}

Abdel-All, M., Abimbola, S., Praveen, D., \& Joshi, R. (2019). What do accredited social health activists need to provide comprehensive care that incorporates non-communicable diseases? Findings from a qualitative study in Andhra Pradesh, India. Human Resources for Health, 17(1), 73.

Armstrong, G., Kermode, M., Raja, S., Suja, S., Chandra, P., \& Jorm, A. F. (2011). A mental health training program for community health workers in India: Impact on knowledge and attitudes. International Journal of Mental Health Systems, 5, 17. Retrieved August 12, 2020 from https://www.org/pmc/articles/PMC3169476 /?report=abstract.

Buttorff, C., Hock, R. S., Weiss, H. A., Naik, S., Araya, R., Kirkwood, B. R., et al. (2012). Évaluation économique d'une intervention de transfert de tâches dans le cadre du traitement des troubles mentaux communs en Inde. Bulletin of the World Health Organization, 90(11), 813-821.

Declaration of Alma-Ata International Conference on Primary Health Care, Alma-Ata, USSR, September 6-12, 1978. Retrieved June 4, 2020 from https://www.who.int/publications/almaata_decla ration_en.pdf?ua $=1$.

Frankel, S., \& Doggett, M.-A. (1992). The community health worker: Effective programmes for developing countries (p. 291). Oxford: Oxford University Press.

Ibrahim, F. A., Nirisha, L., Barikar, M., Kumar, C. N., Chand, P. K., Manjunatha, N., et al. (2020). Identification of psychiatric disorders by rural grass-root health workers: Case series \& implications for the National Mental Health Program of India. Psychiatric Quarterly. Retrieved August 12, 2020 from https://pubmed.ncbi. nlm.nih.gov/32772306/.

Kallivayalil, E. A. (2018). Prioritizing rural and community mental health in India. Indian Journal of Social Psychiatry, 34(4), 285. Retrieved August 12, 2020 from http://www.indjsp.org/artic le. asp? issn $=0971-9962 ;$ year $=2018$; volume $=34$;issue $=4$; spage $=285$; epage $=288$; aulast $=$ Kallivayalil.

Lipekho, S., Esther, R., Puni, K., Sally, T. (2015). Community health workers in rural India: analysing the opportunities and challenges Accredited Social Health Activists (ASHAs) face in realising their multiple roles. Human Resources for Health, 13(1).

Liu, A., Sullivan, S., Khan, M., Sachs, S., \& Singh, P. (2011). Community health workers in global health: Scale and scalability. Mount Sinai Journal of Medicine, 78(3), 419-435.
Manjunatha, N., Kumar, C. N., et al. Karnataka telemedicine and mentoring and monitoring program for complete integration of psychiatry in the general health care. Indian Journal of Psychiatry, $134-154$.

Mishra, A. (2012). The role of the Accredited Social Health Activists in effective health care delivery: Evidence from a study in South Orissa. BMC Proceedings, 6(S1), P1.

Rasaily, S., Sharma, I. L., \& Ongmoo, K. (2017). Capacity building and community process in DMHP implementation in Gyalshing District, Sikkim: Two year report (13-14). The Journal of Medical Research, 3(3), 169-171.

Reddy, S. K., Thirthalli, J., Channaveerachari, N. K., Reddy, K. N., Ramareddy, R. N., Rawat, V. S., et al. (2014). Factors influencing access to psychiatric treatment in persons with schizophrenia: A qualitative study in a rural community. Indian Journal of Psychiatry, 56(1), 54-60.

Scott, K., \& Shanker, S. (2010). Tying their hands? Institutional obstacles to the success of the ASHA community health worker programme in rural north India. AIDS Care-Psychological and Socio-Medical Aspects of AIDS/HIV, 22(Suppl. 2), 1606-1612.

Semahegn, A., Torpey, K., Manu, A., Assefa, N., Tesfaye, G., \& Ankomah, A. (2018). Psychotropic medication non-adherence and associated factors among adult patients with major psychiatric disorders: A protocol for a systematic review. Systematic Reviews, 7(1), 10

Walt, G., \& Gilson, L. (1990). Find in a library: Community health workers in national programmes: Just another pair of hands? Retrieved June 4, 2020 from https://www.worldcat.org/title/ community-health-workers-in-national-programmes-just-anoth er-pair-of-hands/oclc/20826384?page=citation.

Wang, H., Juyal, R., Miner, S., et al. (2012). Performance-based payment system for the ASHAs in India: What does International experience tell us? http://www.intrahealth.org/files/media/perfo rmance-based-payment-system-for-ashas-in-india-what-does-inter national-experience-tell-us-technical-report/PerformanceBase dPaymentSystemASHAsIndiaReport.pdf.

WHO: Task shifting to tackle health worker shortages.HIV/AIDS Programme; strengthening health services to fight HIV/AIDS; WHO/ HSS/2007.03.

XIIth Plan District Mental Health Programme prepared by Policy Group 29th June 2012.

Publisher's Note Springer Nature remains neutral with regard to jurisdictional claims in published maps and institutional affiliations. 